\title{
Aspectos Metrológicos da Técnica Tempo de Voo da Onda Difratada (ToFD) para Utilização em Ensaios Não Destrutivos (ENDs) por Ultrassom
}

\author{
Ruan Carvalho Mayworm¹, Rodrigo Pereira Barretto da Costa-Félix ${ }^{1}$, André Victor Alvarenga ${ }^{1}$ \\ 1 Instituto Nacional de Metrologia, Qualidade e Tecnologia - INMETRO, Divisão de Metrologia Acústica e Vibrações - Diavi, \\ Diretoria de Metrologia Científica e Industrial - Dimci, Duque de Caxias, RJ, Brasil.
}

Recebido: 28 Mar., 2016

Aceito: 29 Set., 2016

E-mail: rcmayworm@gmail.com (RCM)
Resumo: Ensaios Não Destrutivos (END) são amplamente utilizados na indústria. Dentre as principais técnicas de END, as mais utilizadas são baseadas no uso do ultrassom. Uma destas técnicas é o Tempo de Voo da Onda Difratada (ToFD). A técnica ToFD baseia-se no uso de duas sondas angulares colocadas paralelamente sobre a mesma superfície, a uma distância fixa uma da outra, conhecida como Probe Center Separation (PCS). O PCS visa obter o foco das ondas sônicas em uma região específica da peça inspecionada, no entanto, o feixe não atinge totalmente a peça. Com a variação do PCS, a peça poderá ser inspecionada por completo. Portanto, foi testado se, por meio da variação do PCS, é possível minimizar a zona morta, aumentando a confiabilidade da inspeção. Concluiu-se que a variação do PCS tem influência direta sobre a identificação das descontinuidades próximas a superfície ou próximas ao fundo do bloco. Evidenciou que, para descontinuidades superficiais, o PCS menor é mais eficaz, enquanto que para descontinuidades próximas ao fundo do bloco, PCS maiores são mais eficazes. Aspectos metrológicos foram considerados neste trabalho de desenvolvimento tecnológico.

Palavras-chave: Ensaios Não Destrutivos; Ultrassom; ToFD; Metrologia; Distância entre Centro dos Cabeçotes (PCS).

\section{Metrological Aspects of the Time of Flight Diffraction Technique (ToFD) Used in Nondestructive Testing (NDT) by Ultrasound}

\begin{abstract}
The Non-Destructive Testing (NDT) are widely used in industry. Among the main NDT techniques, the most used are based on the use of ultrasound. One of these is the Time of Flight Diffraction Technique (ToFD). The ToFD is based on the use of two angle transducers placed in parallel on the same surface at a fixed distance from one another, known as Probe Center Separation (PCS). The PCS seeks the focus of sonic waves in a part of the inspected point on which to characterize, however, the beam is not totally reaches the workpiece to be inspected. Therefore, it is believed that with the variation of PCS, the piece may be completely inspected. Therefore, it was tested whether, by varying the PCS is possible to minimize the dead zone, increasing the reliability of inspection. It was concluded that the variation of PCS in ToFD technique has direct influence in the identification of discontinuities near the surface or near the bottom of the piece. It was evident that for surface discontinuities the lowest PCS is more effective, whereas for discontinuities near the bottom, larger PCS are most efficient. Metrology is the base of this research of technological development.
\end{abstract}

Key-words: Non-Destructive Testing; Ultrasound; ToFD; Metrology; Probe Center Separation (PCS).

\section{Introdução}

Ensaios Não Destrutivos (END) são amplamente utilizados na indústria, principalmente na avaliação de peças e estruturas mecânicas para a identificação de defeitos, corrosão, falhas ou imperfeições em soldas, constituindo uma das principais ferramentas do controle da qualidade. Dentre as principais técnicas de END, as mais utilizadas são baseadas no uso do ultrassom. Uma destas técnicas é o Tempo de Voo da Onda Difratada (ToFD, sigla em inglês de "Time of Flight Diffraction"), que permite a formação de imagens do objeto ensaiado, possibilitando uma avaliação visual da mesma [1]. 


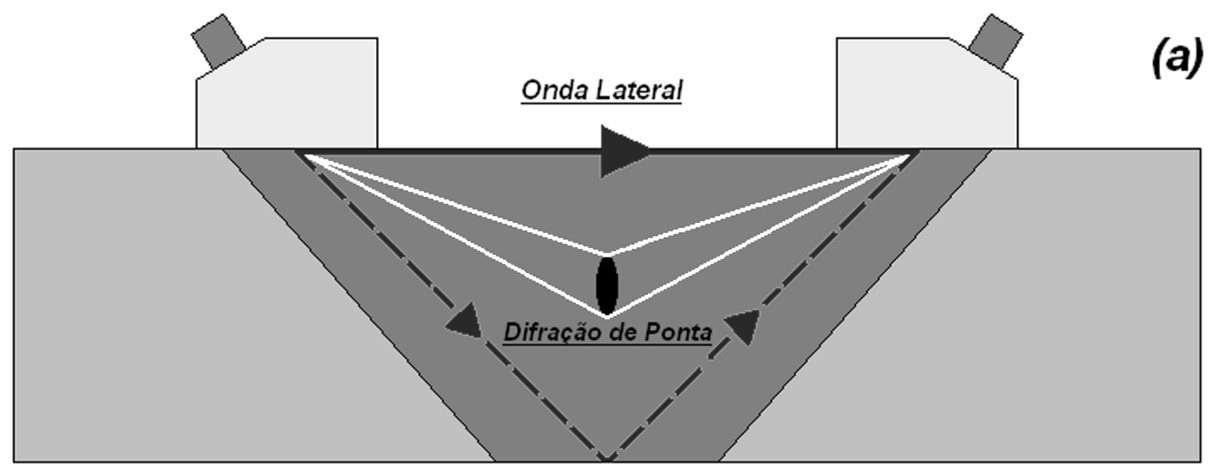

Reflexão da Parede Posterior

(b)

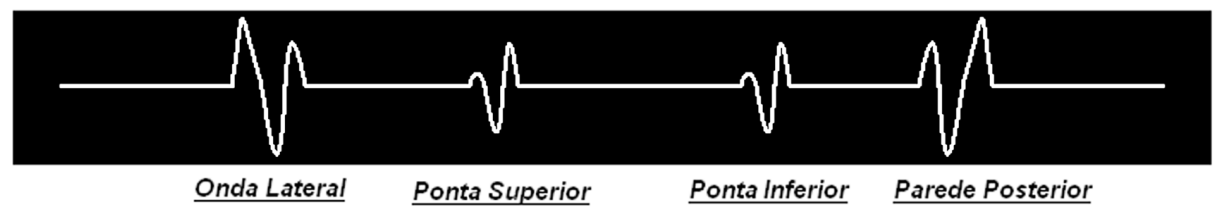

Figura 1. (a) Formação de ondas características do ToFD (b) Exemplo de um sinal tipo A-scan característico do ToFD [2].

A técnica baseia-se no uso de duas sondas angulares (cabeçotes) colocadas paralelamente sobre a mesma superfície, como na Figura 1a, com o objetivo de que um pulso ultrassônico gerado por um transdutor (emissor) seja recebido pelo transdutor oposto (receptor) [3].

A distância entre o centro dos transdutores, denominada de PCS (Probe Center Separation), é ajustada de acordo com a espessura do material a ser inspecionado [4]. O scanner com os cabeçotes é frequentemente movido paralelo à região provável de conter defeitos, como por exemplo, uma linha de solda [5].

Os sinais captados pelo receptor formam duas ondas, uma que viaja ao longo da superfície e outra que é a refletida na parede posterior [2]. Quando um feixe ultrassônico incide em uma descontinuidade, além dos fenômenos já conhecidos de reflexão e transmissão, ocorre também à difração, que consiste na geração de uma onda circular, que se propaga em todas as direções. A detecção das ondas difratadas torna possível estabelecer a presença de descontinuidades. Medindo-se o tempo de voo do pulso, a profundidade de uma extremidade da descontinuidade pode ser calculada por trigonometria, podendo-se então dimensioná-la [6]. A dimensão da descontinuidade é sempre determinada a partir do tempo de voo das ondas difratadas. A amplitude do sinal não é utilizada para estimar essa dimensão. Este processo é simples e é ainda mais eficiente do que os testes radiográficos [7]. Na Figura $1 \mathrm{~b}$, pode-se observar a forma de um sinal A-scan recebido quando detectado algum tipo de descontinuidade.

O ToFD utiliza sinais A-scan e os transforma em uma imagem B-scan. O mostrador tipo A (A-scan display) é basicamente um gráfico de amplitude versus tempo, no qual o eixo horizontal representa na maioria das vezes o tempo decorrido, e em alguns casos podendo representar a distância, e o eixo vertical a amplitude dos ecos. $O$ uso do mostrador tipo A não é limitado à detecção e caracterização de descontinuidades. Ele pode ser utilizado também para medição de espessuras, velocidade de propagação, atenuação e geometria do feixe sônico [7].

O mostrador tipo B (B-scan display) se refere à imagem produzida quando os dados são recolhidos a partir de uma inspeção de ultrassom e são traçados em uma vista de seção transversal, perpendicular ao objeto de ensaio. Ao se colocar a forma de onda recebida pelo transdutor em cada ponto de varredura lado a lado, pode-se gerar uma imagem B-scan característica do ToFD. Os resultados deste método são geralmente apresentados como uma 
imagem em escala de cinza, gerada a partir dos sinais A-scan não retificados. Os sinais positivos tendem para a cor branca, enquanto que os sinais negativos para a cor preta, onde a amplitude se torna a escala de cores como demonstrado na Figura $2[8]$.
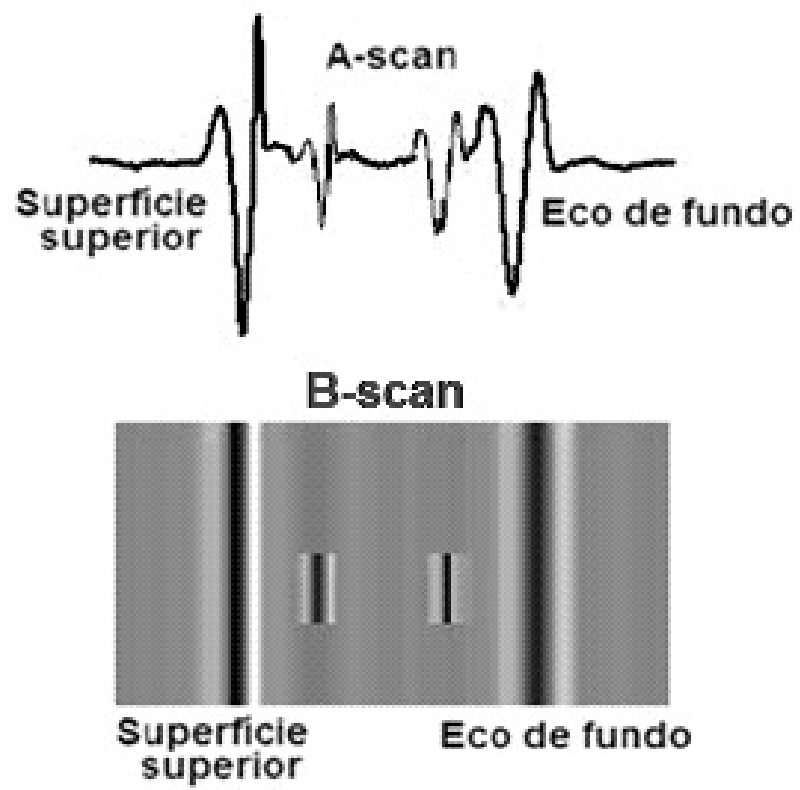

Figura 2. Sinal A-scan característico da técnica ToFD e a imagem B-scan gerada a partir dos sinais A-scan Fonte: elaborado pelo autor.

O PCS é definido pela norma ABNT NBR 16196:2013 Ensaios não destrutivos - Ultrassom — Uso da técnica de tempo de percurso da onda difratada (ToFD) para ensaio em soldas [4], sendo função da espessura da peça a ser inspecionada. O PCS visa direcionar o foco das ondas sônicas em um ponto da peça inspecionada no qual se deseja obter melhores parâmetros para o ensaio, tal como, maior zona de detecção de descontinuidades perceptíveis ao feixe ultrassônico. No entanto, o feixe não atinge totalmente a peça a ser inspecionada, devido à limitação da largura do feixe ultrassônico, gerando uma região na qual nenhuma falha pode ser identificada, conhecida como zona morta. Logo, se houver uma descontinuidade presente na zona morta, a mesma não será detectada, comprometendo a confiabilidade da inspeção.

Como hipóteses para possíveis soluções à limitação descrita, pode-se citar: a utilização de mais de um par de transdutores ou a variação do PCS para uma mesma seção transversal. No entanto, a utilização de mais de um par de transdutores acarreta em um custo mais elevado em relação à variação do PCS, devido ao maior número de componentes necessários (sapatas, por exemplo). Acredita-se que com a variação do PCS, para uma mesma seção transversal, a peça poderá ser inspecionada por completo, devido à possibilidade de variação da posição do ponto focal do feixe ultrassônico. Foi testada experimentalmente a hipótese de que por meio da variação do PCS, para uma mesma seção transversal, é possível eliminar ou minimizar a zona morta, aumentando a confiabilidade da inspeção. A comparação foi feita com princípios metrológicos.

\section{Materiais e Métodos}

O objetivo desse estudo é verificar se, por meio da variação da distância entre os centros dos cabeçotes (PCS), é possível eliminar ou minimizar a zona morta presente na técnica ToFD. Para tal, foi desenvolvido um aplicativo em linguagem Labview ${ }^{\mathrm{TM}}$ no qual, por meio de sinais captados de um sistema de aquisição, é possível gerar imagens B-scan e realizar os cálculos de alguns parâmetros da peça sob ensaio, como por exemplo, a sua espessura. Para a realização dos ensaios, foi confeccionado um corpo de prova em acrílico com descontinuidades conhecidas, o qual teve sua velocidade de propagação ultrassônica calibrada. Para realizar a avaliação dos resultados apresentados pela técnica ToFD, também foram realizadas medições utilizando-se um detector de defeitos e um paquímetro, 
com o objetivo de, ao final dos ensaios, comparar os resultados obtidos. Por fim, foram calculadas as incertezas de medição dos ensaios e utilizou-se o erro normalizado para comparação dos resultados.

\subsection{Corpo de prova}

O corpo de prova utilizado foi um bloco confeccionado em acrílico, denominado bloco A1. O bloco A1 possui aproximadamente $100 \mathrm{~mm}$ de comprimento, $80 \mathrm{~mm}$ de largura e $25 \mathrm{~mm}$ de espessura. Além disso, possui em cada uma das quatro faces, um furo de aproximadamente $1 \mathrm{~mm}$ de diâmetro por $20 \mathrm{~mm}$ de profundidade, cada furo a uma distância diferente da superfície, assim como demonstrado na Figura 3.

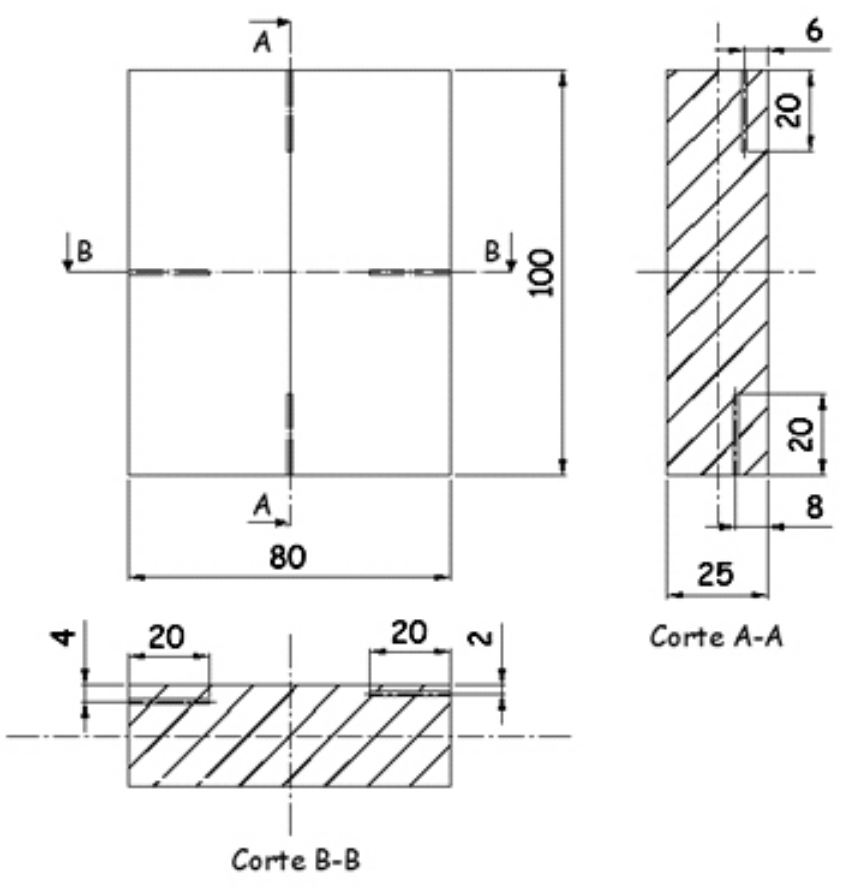

Figura 3. Desenho técnico do bloco A1 (dimensões em mm). Fonte: elaborado pelo autor.

O bloco foi utilizado tanto para o ensaio da técnica ToFD quanto para o ensaio com o detector de defeitos. Optou-se por confeccionar o bloco em acrílico, pois apresenta baixo custo em relação aos blocos metálicos. Além disso, devido à facilidade de manuseio da resina acrílica, é relativamente fácil simular descontinuidades.

\subsection{Detector de defeitos}

O detector de defeitos utilizado foi o modelo EPOCH 600, da marca Olympus, disponível no Laboratório de Ultrassom do Inmetro (Labus). O detector de defeitos oferece funcionalidades avançadas, sendo possível alterar diversas configurações dos ensaios, como por exemplo, o tipo de onda gerada, a velocidade de propagação do material ensaiado, o ganho utilizado, a configuração de medição do tempo de voo, etc [9].

\subsection{Sistema de medição para a técnica ToFD}

Na montagem do sistema de medição foram utilizados os seguintes equipamentos: um detector de defeitos da marca Olympus, modelo EPOCH 600, como gerador de pulsos; um osciloscópio da marca Agilent Technologies, modelo DSO 3024A; dois transdutores (emissor e receptor) da marca Olympus, modelo C543-SM, com frequência de $5 \mathrm{MHz}$ e diâmetro de $6 \mathrm{~mm}$ (tanto para o ensaio pulso-eco, quanto para o ToFD); duas sapatas angulares de 60응 de acrílico, da marca Olympus, modelo ABSA-4T-60; Atenuador da marca JBM Instrumentos, modelo J3054-BB, um cabo de comunicação USB, gel da marca Carbogel ULT como elemento acoplante e um computador contendo o aplicativo desenvolvido em Labview ${ }^{\mathrm{TM}}$. Na Figura 4, pode-se observar o sistema de medição montado. 


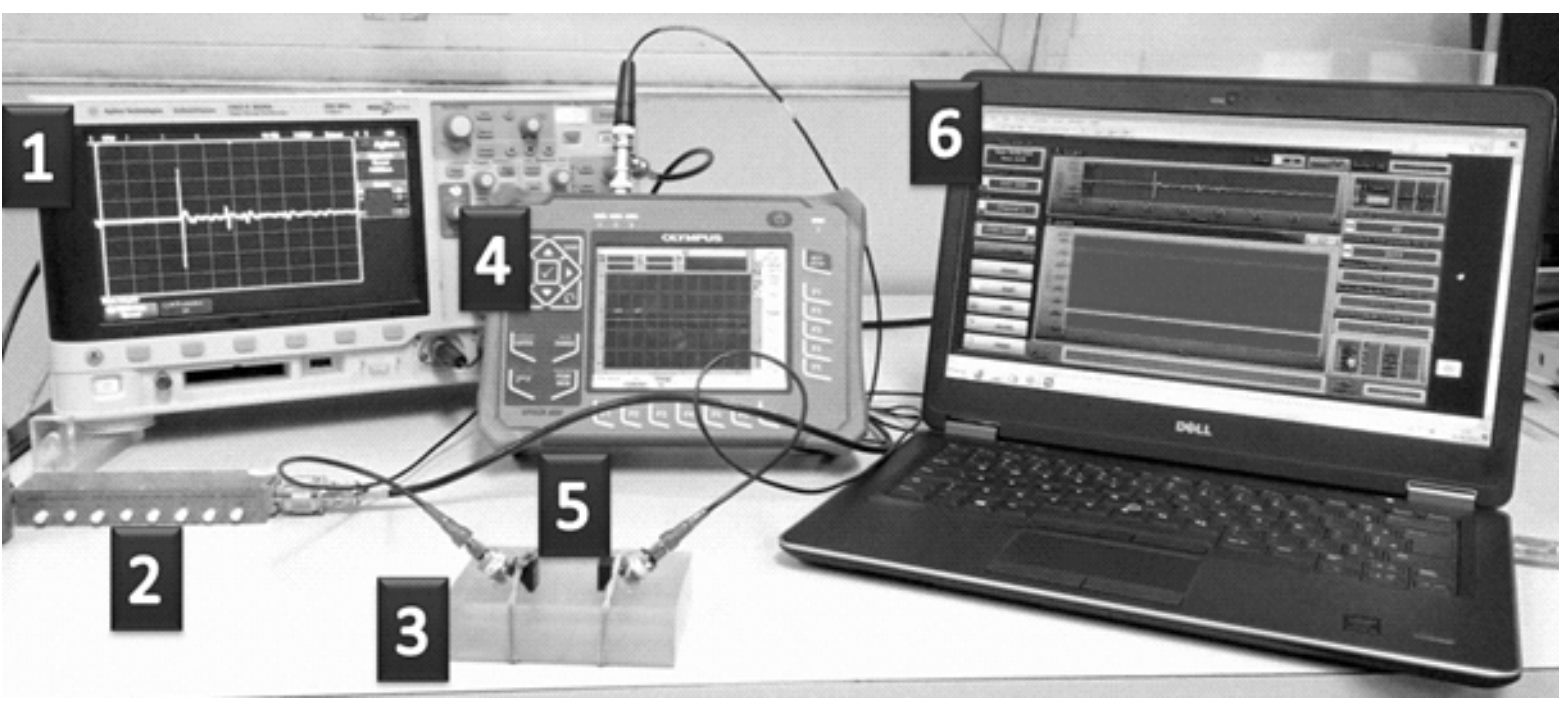

Figura 4. Montagem de Medição: 1) Osciloscópio DSO 3024A; 2) Atenuador JBM; 3) Bloco A1; 4) Detector de Falhas EPOCH 600; 5) Transdutores e Sapatas da Olympus; 6) Computador com o aplicativo em Labview ${ }^{\mathrm{TM}}$.

O detector de defeitos é utilizado como gerador de pulsos elétricos, pois tem a capacidade de gerar pulsos com amplitudes da ordem de $400 \mathrm{~V}$. É importante que o gerador gere sinais com grandes amplitudes, porque devido à atenuação o pulso ultrassônico perde energia ao percorrer o acrílico, dificultando a visualização das ondas difratadas. $\mathrm{O}$ pulso elétrico gerado é transmitido ao transdutor emissor, que o transforma em um pulso ultrassônico, ou seja, uma onda mecânica, que por sua vez percorre todo o material ensaiado. Em seguida, o pulso ultrassônico é detectado pelo receptor (no caso do pulso-eco o emissor e o receptor são o mesmo transdutor). O sinal detectado pelo receptor é apresentado em forma de um sinal tipo A-scan na tela do osciloscópio. Por fim, o sinal é transferido do osciloscópio para o computador com auxílio de um cabo de comunicação USB. De maneira complementar, utiliza-se um atenuador para diminuir a intensidade do sinal enviado para a entrada de trigger externo do osciloscópio, a fim de preservá-lo. $O$ aplicativo desenvolvido em Labview ${ }^{\mathrm{TM}}$ tem como funções principais a transformação dos sinais captados (tipo A-scan) em imagem B-scan e facilitar o cálculo das dimensões do objeto sob ensaio.

\subsection{Aplicativo}

O aplicativo tem como função a geração de imagens construídas através dos sinais captados pelo sistema de aquisição, sendo muito comum a utilização dos mesmos em ensaios não destrutivos, pois são capazes de apresentar resultados confiáveis, além de serem mais práticos e, na maioria das vezes, aumentar a velocidade e a confiabilidade da inspeção [10].

Optou-se por utilizar o Labview ${ }^{\mathrm{TM}}$ para a construção do aplicativo, pois é um software de design de sistemas poderoso, construído especificamente para tarefas executadas por engenheiros e cientistas e composto por ferramentas capazes de desenvolver e implantar sistemas de medição e controle [11].

O aplicativo foi desenvolvido de forma a facilitar a utilização pelo operador. O software é capaz de transformar os sinais A-scan em imagens B-scan, além disso, possui outras funções complementares, como por exemplo: o cálculo da espessura, profundidade e altura do defeito, por meio de cursores; permite a análise posterior dos sinais adquiridos; aceita a utilização de outros modelos de equipamentos, como por exemplo, diferentes osciloscópios; realiza o processamento de sinais, a fim de evidenciar difrações e reflexões com amplitudes relativamente pequenas, aumentando o contraste da imagem B-scan, entre outras. Na Figura 5, é apresentado o painel frontal do programa desenvolvido.

Para a medição da espessura e das possíveis descontinuidades do objeto ensaiado, o programa possui dois pares de cursores, que a partir do tempo de voo obtido dos sinais adquiridos, calculam as dimensões desejadas. As fórmulas utilizadas para este cálculo foram baseadas no trabalho de Mondal e Sattar [12]. 


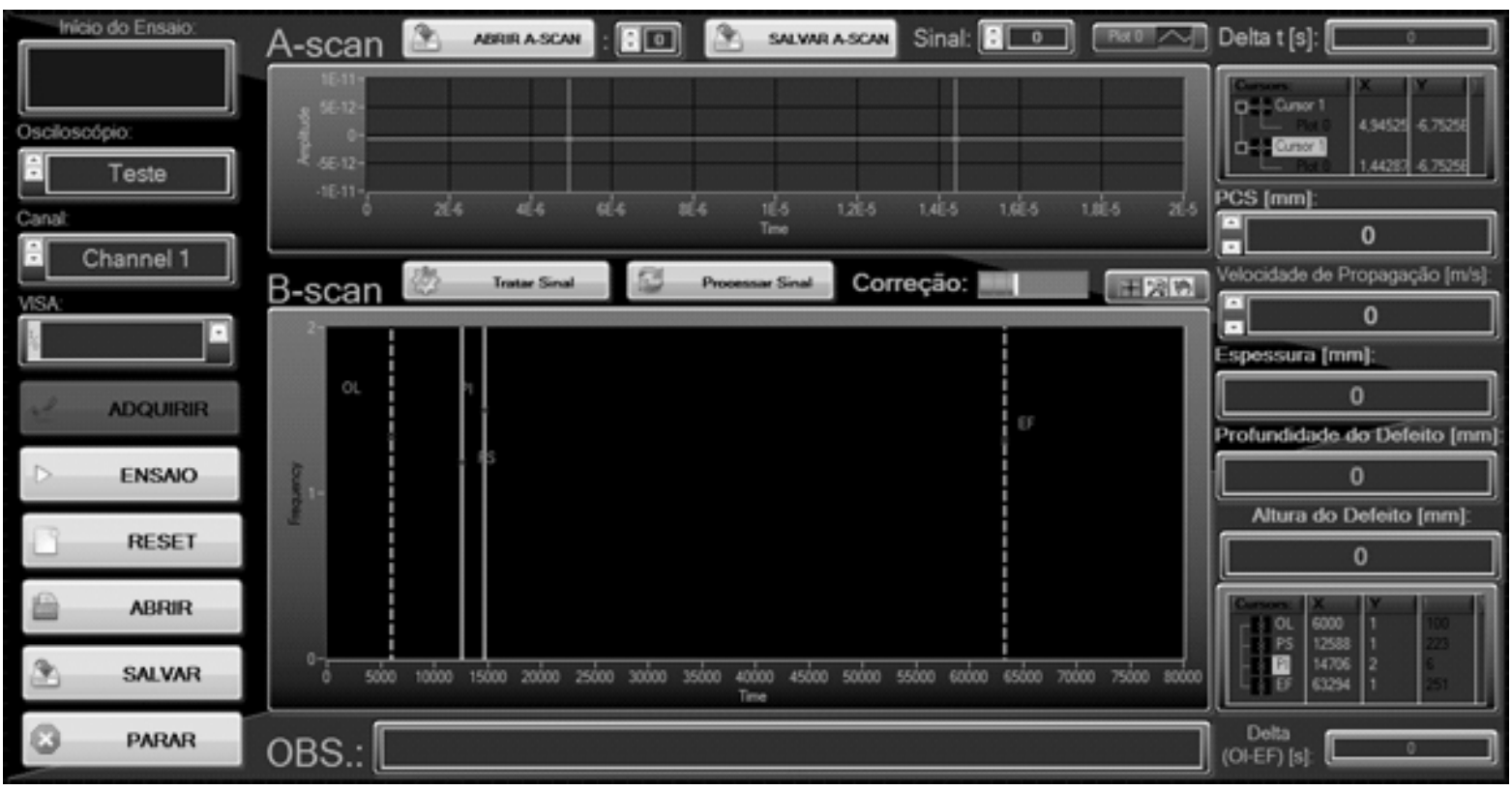

Figura 5. Painel frontal do programa desenvolvido em Labview ${ }^{\mathrm{TM}}$.

Para o cálculo da espessura do material são utilizados dois cursores, sendo eles o cursor OL (Onda Lateral) e o cursor EF (Eco de Fundo). Posicionando o cursor OL sobre a parte da imagem B-scan referente à onda lateral e o cursor EF sobre o eco de fundo, é possível obter a diferença de tempo de voo entre a onda lateral e o eco de fundo, e a partir da Equação 1, pode-se obter a espessura do material em função da diferença de tempo entre os cursores.

$$
\mathrm{h}=\sqrt{\frac{\left(\mathrm{t}_{\mathrm{bw}}-\mathrm{t}_{\mathrm{L}}\right)^{2} \cdot v^{2}}{4}+\mathrm{S} \cdot v \cdot\left(\mathrm{t}_{\mathrm{bw}}-\mathrm{t}_{\mathrm{L}}\right)}
$$

Na qual:

$t_{b w}$ - Tempo de chegada da onda de fundo [s];

$t_{L}$ - Tempo de chegada da onda lateral [s];

h - Espessura do material [m];

2.S - Distância de separação entre as duas sondas [m];

$v$ - Velocidade da onda longitudinal $\left[\mathrm{m} \cdot \mathrm{s}^{-1}\right]$.

Para o cálculo da profundidade do defeito, ou seja, a distância da superfície até a descontinuidade, é utilizado o cursor OL (Onda Lateral) e o cursor PS (Ponta Superior). Por meio dos cursores, obtêm-se a diferença de tempo de voo entre a onda lateral e a difração da parte superior da descontinuidade. Através da Equação 2, obtêm-se a profundidade da descontinuidade.

$$
\mathrm{d}=\sqrt{\frac{\left(\mathrm{t}_{1}-\mathrm{t}_{\mathrm{L}}\right)^{2} \cdot v^{2}}{4}+\mathrm{S} \cdot v \cdot\left(\mathrm{t}_{1}-\mathrm{t}_{\mathrm{L}}\right)}
$$

Na qual:

$\mathrm{t}_{1}$ - Tempo de chegada da ponta superior [s];

$\mathrm{d}$ - Profundidade da descontinuidade $[\mathrm{m}]$.

Para o cálculo da altura do defeito, são utilizados os cursores OL (Onda Lateral) e o cursor PI (Ponta Inferior). Por meio dos cursores, obtêm-se a diferença de tempo de voo entre a onda lateral e a difração da parte inferior da descontinuidade. Logo, por meio da Equação 3 obtêm-se a altura da descontinuidade. 


$$
\mathrm{L}=\sqrt{\frac{\left(\mathrm{t}_{2}-\mathrm{t}_{\mathrm{L}}\right)^{2} \cdot v^{2}}{4}+\mathrm{S} \cdot v \cdot\left(\mathrm{t}_{2}-\mathrm{t}_{\mathrm{L}}\right)}-\mathrm{d}
$$

Na qual:

$\mathrm{t}_{2}$ - Tempo de chegada da ponta inferior [s];

$\mathrm{L}-$ Altura da descontinuidade $[\mathrm{m}]$.

\subsection{Protocolo de ensaio}

A fim de tornar os resultados dos ensaios comparáveis, padronizou-se a forma de execução dos ensaios criando-se um protocolo de medição. Portanto, todas as medições foram repetidas três vezes e realizadas utilizando-se o detector de defeitos, o paquímetro e a técnica ToFD para diferentes distâncias entre os centros dos cabeçotes (PCS), sendo elas: $15 \mathrm{~mm}, 20 \mathrm{~mm}, 25 \mathrm{~mm}$ e $30 \mathrm{~mm}$.

No bloco A1, nas posições acima dos furos, mediu-se a espessura do bloco, a profundidade do defeito (distância da superfície até o início do furo) e a altura do defeito (diâmetro do furo), como demonstrado na Figura 6. Cabe ressaltar que as medições foram realizadas tanto pela superfície do bloco, quanto pelo fundo do bloco, obtendo-se oito pontos de medição.

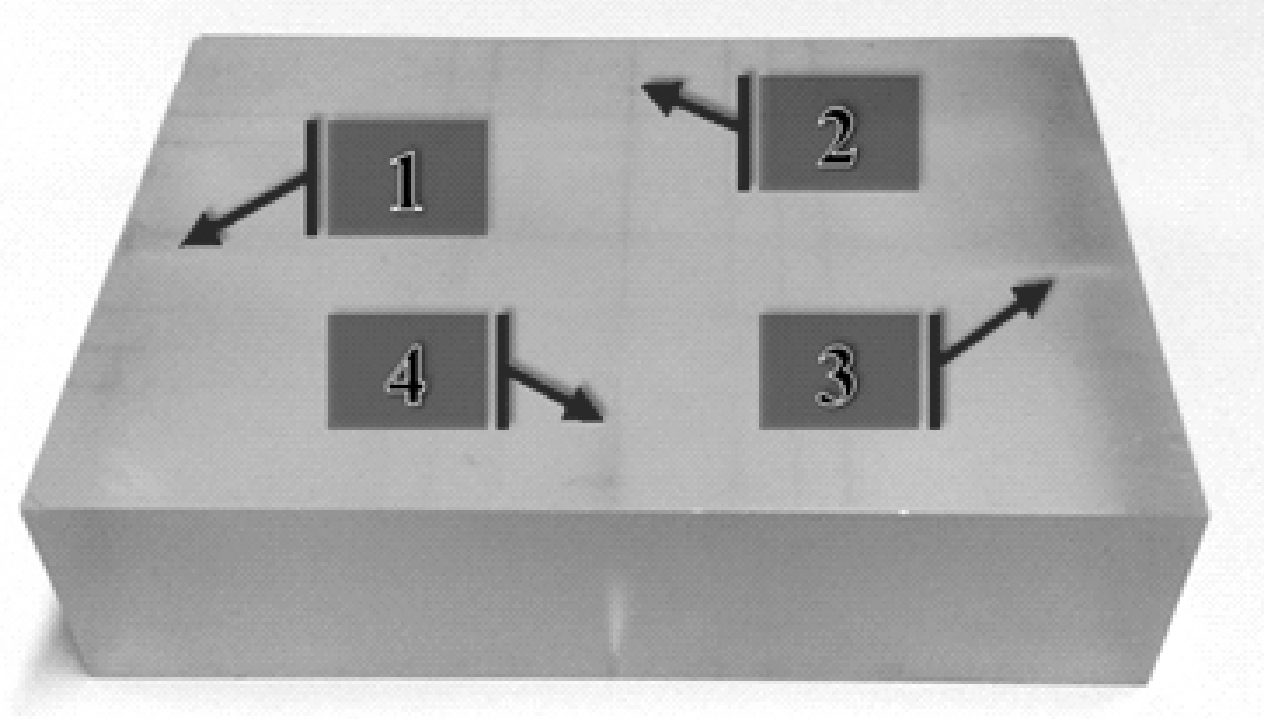

Figura 6. Bloco A1 e os pontos utilizados nas medições.

\subsection{Cálculo da incerteza de medição}

Com o intuito de se apresentar uma indicação quantitativa da qualidade dos resultados, realizou-se o cálculo das incertezas.

Para uma relação genérica $h=f\left(x_{\mathrm{j}}\right)$, pode-se utilizar a Equação 4 para o modelo de incerteza [13]:

$$
u_{c}^{2}=\sum_{j-1}^{N}\left(\frac{d h}{d x_{j}}\right)^{2} \cdot u_{j}^{2}
$$

Onde $u_{c}$ é a incerteza padrão combinada associada com o resultado final da medição (ou cálculo) de $h$ e $u_{j}$ a incerteza padrão, avaliada como tipo A ou tipo B, associada a cada parâmetro variável $x_{j}$ utilizado para expressar o valor de $h$. 
Na grande maioria dos casos, a média aritmética é a melhor estimativa para o valor esperado de uma quantidade que varia aleatoriamente e para a qual se tem $\mathrm{n}$ leituras independentes obtidas sob condições de repetibilidade [14]. Assim, quando a estimativa de uma grandeza de entrada foi obtida de $n$ medições sob condições de repetibilidade, a incerteza do tipo A é obtida pela estimativa do desvio-padrão da média, pela Equação 5 [13]:

$$
\mathrm{u}_{\mathrm{A}}=\frac{\mathrm{s}}{\sqrt{\mathrm{n}}}
$$

Na qual:

$\mathrm{u}_{\mathrm{A}}=$ Incerteza do Tipo A;

$\mathrm{s}=$ Desvio-padrão amostral;

$\mathrm{n}=$ Número de medições realizadas.

Para a estimativa de uma grandeza de entrada $x_{i}$, que não tenha sido obtida de observações repetidas, a incerteza padrão $u_{B}\left(x_{i}\right)$ é avaliada pelo julgamento específico baseado em todas as informações disponíveis sobre a variabilidade de $x_{i}$. No conjunto destas informações são incluídos: informações prévias de medição; experiência ou conhecimento geral do comportamento e propriedades dos instrumentos e materiais relevantes; especificações do fabricante; informações de relatórios de calibração e outras especificações; e a incerteza transmitida pelas informações de referências obtidas de manuais [13].

\subsubsection{Incerteza de medição dos cursores do ToFD}

Para o cálculo da incerteza de medição dos cursores utilizou-se a incerteza proveniente das três repetições como incerteza do tipo A. Como as variáveis das equações utilizadas para o cálculo por meio dos cursores são $\mathrm{S}$ (PCS/2), v (velocidade) e t (tempo), utilizou-se, no caso do v e t, a incerteza do tipo B oriunda do certificado de calibração. Logo, foi necessário calcular apenas a incerteza do tipo B para a régua, utilizada para a medição do PCS, que se trata de uma distribuição triangular com resolução de $1 \mathrm{~mm}$. Após os cálculos de todas as incertezas, calculou-se a incerteza combinada final e a incerteza expandida para cada medição realizada pelos cursores espessura, profundidade do defeito e altura do defeito.

\subsubsection{Incerteza de medição do detector de defeitos}

A fim de realizar o cálculo de incerteza das medições realizadas pelo EPOCH 600, fez-se necessário identificar suas fontes de incerteza, a saber: repetição (tipo A), calibração da velocidade de propagação ultrassônica do bloco (tipo B) e a resolução do equipamento (tipo B). A incerteza da repetição é proveniente das três medições realizadas; a da calibração se refere aos valores oriundos do certificado de calibração da velocidade ultrassônica do bloco; e por fim, a resolução do equipamento que é igual a 0,01 mm, que se trata de uma distribuição retangular. Após a determinação das fontes de incerteza, calculou-se a incerteza combinada final e a incerteza expandida para cada medição realizada pelo equipamento.

\subsubsection{Incerteza de medição do paquímetro}

Para o cálculo das medições realizadas utilizando-se o paquímetro, considerou-se a incerteza do tipo A oriunda das três repetições, as incertezas do tipo B referentes a resolução do paquímetro, sendo a mesma 0,01 mm com distribuição retangular; e a incerteza de medição do certificado de calibração, sendo a mesma 0,0086 mm para $k_{0,95}=2,06$.

\subsection{Comparação dos resultados}

A fim de comparar os resultados obtidos das diferentes técnicas, utilizou-se o Erro Normalizado $\left(E_{n}\right)$. Este é realizado através da comparação entre pares de valores e incertezas, seguindo a ABNT NBR ISO/IEC 17043:2011 [15] (Avaliação da conformidade - Requisitos gerais para ensaios de proficiência). Logo, a análise estatística será realizada através da Equação 6: 


$$
\mathrm{E}_{\mathrm{n}}=\left|\frac{\mathrm{P}_{\mathrm{r}}^{\mathrm{P}}-\mathrm{P}_{\mathrm{r}}^{\mathrm{S}}}{\sqrt{\mathrm{U}_{\mathrm{P}}^{2}+\mathrm{U}_{\mathrm{S}}^{2}}}\right|
$$

Na qual:

$\mathrm{P}_{\mathrm{r}}^{\mathrm{P}}=$ valor da grandeza obtida com o sistema de medição 1 (padrão);

$\mathrm{P}_{\mathrm{r}}^{\mathrm{s}}=$ valor da grandeza obtida com outro sistema de medição 2;

$U_{p}=$ é a incerteza expandida ( $\left.p=0,95\right)$ obtida com o sistema de medição 1 (padrão);

$U_{s}=$ é a incerteza expandida $(p=0,95)$ obtida com o sistema de medição 2 .

Com base nesta análise estatística, consideram-se resultados aceitáveis, isto é, que não são estatisticamente diferentes, aqueles em que $E_{n} \leq 1$ [15].

\section{Resultados e Discussão}

Foram medidos, quando possível, a espessura do bloco, assim como a profundidade e altura dos defeitos. Essas medições foram repetidas por 3 vezes e realizadas utilizando-se a técnica pulso-eco, o paquímetro e a técnica ToFD com diferentes PCS.

Em alguns casos, era possível observar a presença de um defeito, no entanto, impossível de mensurá-lo, pois os resultados obtidos não condiziam com o real. Nesses casos, utilizou-se o código "I" (identificável). Quando não foi observada nenhum artefato na imagem B-scan (técnica ToFD) ou A-scan (técnica pulso-eco), utilizou-se o código "NI" (não identificável).

Ambas as técnicas utilizadas foram eficazes no dimensionamento da espessura do bloco. Entretanto, os valores médios apresentam desvios entre as técnicas. Na Tabela 1 são apresentados os resultados obtidos para o ensaio de medição de profundidade.

Tabela 1. Resultados dos ensaios no bloco A1 para medição da profundidade do defeito [mm].

\begin{tabular}{|c|c|c|c|c|c|c|}
\hline Ponto & Pulso-eco & ToFD $15 \mathrm{~mm}$ & ToFD $20 \mathrm{~mm}$ & $\begin{array}{c}\text { ToFD } \\
25 \mathrm{~mm}\end{array}$ & $\begin{array}{c}\text { ToFD } \\
\mathbf{3 0 ~ m m}\end{array}$ & Paquímetro \\
\hline $2 \mathrm{~mm}$ da superfície & 1,96 & I & $\mathrm{NI}$ & $\mathrm{NI}$ & $\mathrm{NI}$ & 1,39 \\
\hline $4 \mathrm{~mm}$ da superfície & 3,96 & 3,74 & 3,97 & I & $\mathrm{NI}$ & 3,79 \\
\hline $6 \mathrm{~mm}$ da superfície & 6,14 & 7,17 & 6,08 & 6,18 & 1 & 5,59 \\
\hline $8 \mathrm{~mm}$ da superfície & 7,89 & 8,60 & 8,25 & 8,25 & 7,77 & 7,56 \\
\hline $8 \mathrm{~mm}$ do fundo & 16,68 & 16,43 & 16,40 & 16,84 & 16,93 & 16,65 \\
\hline $6 \mathrm{~mm}$ do fundo & 18,47 & 18,38 & 17,87 & 18,41 & 18,50 & 18,56 \\
\hline $4 \mathrm{~mm}$ do fundo & 20,60 & 20,18 & 20,08 & 20,17 & 20,46 & 20,62 \\
\hline $2 \mathrm{~mm}$ do fundo & 22,85 & $\mathrm{NI}$ & 22,18 & 22,26 & 22,54 & 22,83 \\
\hline
\end{tabular}

Para o cálculo da profundidade do defeito, observa-se que apenas a técnica pulso-eco foi capaz de dimensiona-la em todos os pontos de medição, ademais, percebe-se que quanto menor o valor de PCS, a técnica ToFD é capaz de detectar descontinuidades mais próximas da superfície, mas incapaz de detectar as descontinuidades próximas ao fundo. Para valores de PCS maiores, a eficácia da técnica ToFD na detecção de descontinuidades superficiais é reduzida, no entanto, a detecção de descontinuidades próximas ao fundo aumenta. Por fim, para o dimensionamento da altura do defeito, somente a técnica ToFD foi eficaz, obtendo êxito na detecção da altura do defeito em alguns pontos.

Observou-se que, para os ensaios realizados pela técnica ToFD, as fontes de incerteza de maior contribuição sobre a incerteza final foram a repetição e a resolução da régua, obtendo uma contribuição média de $51 \%$ e $48 \%$, respectivamente. Portanto, caso se deseje obter incertezas menores, seria necessário utilizar um equipamento com maiores resoluções para o ajuste do PCS, como por exemplo, um paquímetro. 
Para os ensaios utilizando o detector de defeitos observou-se que a repetição é a fonte de incerteza que mais contribui para a incerteza final, chegando a contribuir com até 98,9\%. Logo, caso necessário obter incertezas menores para o detector de defeitos, seria necessário realizar uma quantidade maior de medições.

Para os ensaios realizados pelo paquímetro, notou-se que, assim como nos ensaios com o detector de defeitos, a repetição é a fonte de incerteza que mais contribui para a incerteza final, chegando a contribuir com até 76,9\%. Na Tabela 2, são apresentados os valores de incerteza, assim como os fatores de abrangência, obtidos para uma probabilidade de abrangência de $95 \%$, no ensaio de medição de profundidade do defeito.

Para a determinação do erro normalizado, considerou-se os valores do paquímetro como referência, pois não dependem de outras grandezas de entrada, tal como a velocidade, além de apresentarem as menores incertezas. $\mathrm{Na}$ Tabela 3, são apresentados os valores de erro normalizado dos ensaios de profundidade do defeito realizados no bloco A1.

Tabela 2. Incertezas obtidas para o ensaio de profundidade do defeito [mm].

\begin{tabular}{|c|c|c|c|c|c|c|c|c|c|c|c|c|}
\hline \multirow{2}{*}{ Ponto } & \multicolumn{2}{|c|}{ Pulso-eco } & \multicolumn{2}{|c|}{ ToFD $15 \mathrm{~mm}$} & \multicolumn{2}{|c|}{ ToFD $20 \mathrm{~mm}$} & \multicolumn{2}{|c|}{ ToFD 25 mm } & \multicolumn{2}{|c|}{ ToFD $30 \mathrm{~mm}$} & \multicolumn{2}{|c|}{ Paquímetro } \\
\hline & $\mathbf{k}_{0,95}$ & $\mathbf{U}$ & $\mathbf{k}_{0,95}$ & $\mathbf{U}$ & $\mathbf{k}_{0,95}$ & $\mathbf{U}$ & $\mathbf{k}_{0,95}$ & $\mathbf{U}$ & $\mathbf{k}_{0,95}$ & $\mathbf{U}$ & $\mathbf{k}_{0,95}$ & $\mathbf{U}$ \\
\hline $2 \mathrm{~mm}$ da superfície & 4,30 & 0,60 & - & - & - & - & - & - & - & - & 4,30 & 0,08 \\
\hline $4 \mathrm{~mm}$ da superfície & 4,30 & 0,18 & 3,18 & 0,98 & 2,14 & 0,20 & - & - & - & - & 2,16 & 0,01 \\
\hline $6 \mathrm{~mm}$ da superfície & 4,30 & 0,26 & 2,07 & 0,34 & 2,78 & 0,77 & 3,18 & 0,73 & - & - & 2,16 & 0,01 \\
\hline $8 \mathrm{~mm}$ da superfície & 2,05 & 0,01 & 2,36 & 0,69 & 2,78 & 0,95 & 3,18 & 1,03 & 2,00 & 0,16 & 4,30 & 0,01 \\
\hline $8 \mathrm{~mm}$ do fundo & 2,78 & 0,05 & 1,97 & 0,33 & 2,45 & 1,21 & 2,26 & 0,68 & 2,57 & 1,07 & 4,30 & 0,07 \\
\hline $6 \mathrm{~mm}$ do fundo & 4,30 & 0,12 & 2,04 & 0,51 & 2,57 & 1,32 & 2,23 & 0,69 & 2,36 & 0,99 & 3,18 & 0,03 \\
\hline $4 \mathrm{~mm}$ do fundo & 2,31 & 0,04 & 1,96 & 0,29 & 2,07 & 0,53 & 1,99 & 0,33 & 2,36 & 0,77 & 4,30 & 0,05 \\
\hline $2 \mathrm{~mm}$ do fundo & 3,18 & 0,09 & - & - & 2,05 & 0,53 & 2,10 & 0,57 & 2,57 & 1,28 & 3,18 & 0,03 \\
\hline
\end{tabular}

Tabela 3. Erro Normalizado calculado para os ensaios de profundidade do defeito em referência ao Paquímetro [mm].

\begin{tabular}{lccccc}
\hline \multicolumn{1}{c}{ Ponto } & Pulso-eco & ToFD 15 $\mathbf{~ m m}$ & ToFD 20 $\mathbf{~ m m}$ & $\begin{array}{c}\text { ToFD } \\
\mathbf{2 5} \mathbf{~ m m}\end{array}$ & $\begin{array}{c}\text { ToFD } \\
\mathbf{3 0} \mathbf{~ m m}\end{array}$ \\
\hline 2 mm da superfície & 0,95 & - & - & - & - \\
4 mm da superfície & 0,97 & 0,04 & 0,91 & - & - \\
6 mm da superfície & $\mathbf{2 , 0 6}$ & $\mathbf{4 , 5 8}$ & 0,64 & 0,81 & - \\
8 mm da superfície & $\mathbf{2 , 8 2}$ & $\mathbf{1 , 4 8}$ & 0,71 & 0,66 & $\mathbf{1 , 0 3}$ \\
8 mm do fundo & 0,34 & 0,68 & 0,21 & 0,27 & 0,26 \\
6 mm do fundo & 0,66 & 0,34 & 0,52 & 0,21 & 0,06 \\
4 mm do fundo & 0,35 & $\mathbf{1 , 4 9}$ & $\mathbf{1 , 0 2}$ & $\mathbf{1 , 3 7}$ & 0,21 \\
2 mm do fundo & 0,29 & - & $\mathbf{1 , 2 3}$ & 0,99 & 0,22 \\
\hline
\end{tabular}

A maioria dos resultados obtidos nos ensaios de espessura e profundidade do defeito no bloco A1 utilizando-se a técnica pulso-eco e ToFD obtiveram $\mathrm{E}_{n} \leq 1$. Portanto, pode-se afirmar que essas medições não são estatisticamente diferentes das medições realizadas pelo paquímetro. Para o ensaio de altura de defeito, todos os valores do erro normalizado, onde possível mensura-los, foram menores do que 1. Consequentemente, não são estatisticamente diferentes dos resultados apresentados pelo paquímetro.

\section{Conclusões}

Com base nos resultados apresentados, pode-se concluir que é necessário escolher adequadamente a técnica de END a ser utilizada, uma vez que a escolha inadequada pode influenciar nos resultados apresentados, podendo vir comprometer a confiabilidade da inspeção.

As incertezas obtidas demonstraram que as medições realizadas com paquímetro são as mais confiáveis, devido a não dependerem da velocidade de propagação e possuírem menores incertezas. Todavia, medições com o 
paquímetro não são viáveis para descontinuidades presentes no interior de objetos. Entre as técnicas de ultrassom, a pulso-eco apresentou incertezas relativamente menores quando comparada ao ToFD, o que já se esperava, pois, a técnica pulso-eco possui menos fontes de contribuição para a incerteza, quando comparada ao ToFD. As maiores incertezas apresentadas pela técnica ToFD tem como principais fontes de contribuição a resolução da régua e a repetição, obtendo uma contribuição média de $48 \%$ e $51 \%$, respectivamente. Portanto, seria necessário utilizar outro equipamento com maior resolução para o ajuste do PCS, como por exemplo, um paquímetro, a fim de reduzir a incerteza da técnica ToFD. Cabe ressaltar que está é uma análise da incerteza praticada em laboratório e o aumento do número de repetições, bem como a uso do paquímetro podem não ser viáveis em campo.

A técnica pulso-eco mostrou-se eficiente no dimensionamento da espessura e profundidade dos defeitos, quando comparada a técnica ToFD, obtendo uma quantidade maior de pontos não estatisticamente diferentes em relação ao paquímetro. No entanto, a técnica pulso-eco não obteve êxito no dimensionamento da altura do defeito. Por outro lado, a técnica ToFD apresentou resultados consistentes, permitindo que se pudesse dimensionar a espessura, profundidade do defeito e altura do defeito. Por outro lado, a técnica ToFD apresentou resultados consistentes, permitindo que se pudesse dimensionar a espessura, profundidade do defeito e altura do defeito. Além disso, foi possível identificar descontinuidades em posições onde a técnica pulso-eco não se mostrou eficaz.

A variação do PCS na técnica ToFD mostrou que a distância entre o centro dos cabeçotes tem influência direta sobra a identificação de descontinuidades próximas a superfície ou próximas ao fundo do bloco. Evidenciou-se que para descontinuidades superficiais o PCS menor é mais eficiente, enquanto que para descontinuidades próximas ao fundo do bloco, PCS maiores são mais adequados. Considerando os resultados apresentados, destaca-se que com a variação do PCS, as zonas mortas podem vir a ser minimizadas, aumentando a confiabilidade da técnica.

Por fim, conclui-se que o ToFD é uma técnica adequada para a identificação de falhas e descontinuidades em peças e equipamentos, independente da orientação e dimensão da mesma, permitindo até, que se dimensione a profundidade e altura das descontinuidades em alguns casos. No entanto, quando se deseja dimensionar a espessura da peça sob ensaio ou a profundidade de descontinuidades, a técnica pulso-eco se mostra mais confiável, tornando-se uma alternativa confiável de ensaio.

\section{Referências}

[1] Associação Brasileira de Ensaios Não Destrutivos e Inspeção [página da internet]. São Paulo: ABENDI; 2015. [acesso em 24 ago. 2015]. Disponível em: http://www.abendi.org.br/abendi/

[2] Mayworm RC, Alvarenga AV, Costa-Felix RPB. A metrological based realization of time-of-flight diffraction technique. Physics Procedia. 2015;70:590-593. http://dx.doi.org/10.1016/j. phpro.2015.08.029.

[3] Browne B. Time of flight diffraction its limitations - actual \& perceived. NDTnet. 1997;2(9).

[4] Associação Brasileira de Normas Técnicas. ABNT NBR 16196:2013: ensaios não destrutivos - ultrassom - uso da técnica de tempo de percurso da onda difratada (ToFD) para ensaio em soldas. Rio de Janeiro: ABNT; 2013.

[5] Souza RR. Dimensionamento de defeitos em blocos de aço carbono através da técnica ToFD [dissertação de mestrado]. Porto Alegre: Programa de Pós-Graduação em Engenharia de Minas, Metalúrgica e de Materiais, Universidade Federal do Rio Grande do Sul; 2009.

[6] Charlesworth JP, Temple JAG. Application of ultrasonic time of flight diffraction. 2. ed. Berlin: Springer; 2001.

[7] Subbaratnam R, Saju T, Abraham B, Venkatraman B, Baldev R. Immersion and ToFD (I-TOFD): a novel combination. Journal of Nondestructive Evaluation. 2011;30:137. http://dx.doi. org/10.1007/s10921-011-0101-0.

[8] Hecht A. Time of Flight Diffraction Technique (ToFD) - an ultrasonic testing a method for all applications?. NDTnet. 1997;2(9).

[9] Olympus. Epoch 600: manual do usuário. DMTA-10006-01PT - Revisão A. Waltham: Olympus; 2013.

[10] Silva BP. Avaliação de falhas em revestimentos anticorrosivos pelo método de ensaio não destrutivo por ultrassom. Rio de Janeiro: Escola Politécnica; 2011.

[11] National Instruments [página da internet]. São Paulo: National Instruments; 2015 [acesso em 1 set. 2015]. Disponível em: http://www.ni.com/labview/

[12] MondalS, Sattar T. An overview TOFD method and its mathematical model. NDTnet. 2000;5(4).

[13] Instituto Nacional de Metrologia, Qualidade e Tecnologia. GUM - Guia para a Expressão da Incerteza de Medição. 3. ed. Duque de Caxias: INMETRO; 2003.

[14] Instituto Nacional de Metrologia, Qualidade e Tecnologia. VIM - Vocabulário Internacional de Metrologia - Conceitos fundamentais e gerais e termos associados (VIM 2012). Duque de Caxias: INMETRO; 2012.

[15] Associação Brasileira de Normas Técnicas. ABNT NBR ISO/IEC 17043:2011: avaliação da conformidade - requisitos gerais para ensaios de proficiência. Rio de Janeiro: ABNT; 2011. 